\title{
Lithospheric structure and deformation in SE Tibet revealed by ambient noise and earthquake surface wave tomography: Recent advances and perspectives*
}

\author{
Huajian Yao* \\ Laboratory of Seismology and Physics of Earth's Interior, School of Earth and Space Sciences, \\ University of Science and Technology of China, Hefei 230026, China
}

\begin{abstract}
High-resolution lithospheric structure is essential for understanding the tectonic evolution and deformation patterns of the southeastern Tibetan plateau. This is now possible due to recent advances in ambient noise and earthquake surface wave tomography, and great improvements in data coverage from dense portable array stations deployed in SE Tibet. In this review paper, I first give a brief overview of the tomographic methods from ambient noise and earthquake surface waves, and then summarize the major findings about the lithospheric structure and deformation in SE Tibet revealed by ambient noise and earthquake surface wave tomography as well as by other seismic and geophysical observations. These findings mainly include the 3-D distribution of mechanically weak zones in the mid-lower crust, lateral and vertical variations in radial and azimuthal anisotropy, possible interplay of some fault zones with crustal weak zones, and importance of strike-slip faulting on upper crustal deformation. These results suggest that integration of block extrusion in the more rigid upper-middle crust and channel flow in the more ductile mid-lower crust will be more compatible with the current geophysical observations. Finally I discuss some future perspective researches in SE Tibet, including array-based tomography, joint inversion using multiple seismic data, and integration of geodynamic modeling and seismic observations.
\end{abstract}

Key words: SE Tibet; lithospheric structure; deformation; ambient noise; earthquake surface waves CLC number: P315.3

Document code: A

\section{Introduction}

The collision of the Indian and Eurasian plates, which began at approximately $50 \mathrm{Ma}$ (Molnar et al., 1993; Royden et al., 2008), has produced (1) the world's largest plateau with an average surface elevation of $5 \mathrm{~km}$ (Figure 1) and a crust thickness of up to $80 \mathrm{~km}$ (Mooney et al., 1998), (2) the magnificent mountain ranges of the Himalaya, Karakorum, Tianshan, Kunlunshan, Qilianshan, and Longmenshan, (3) transport of (crust and, perhaps, lithosphere) material from the central Tibetan plateau towards the east, with bifurcation around the rigid Sichuan basin toward SW China and the northeastern Tibetan plateau margin (Figure 1)

\footnotetext{
* Received 28 September 2012; accepted in revised form 22 October 2012; published 10 December 2012.

+ Corresponding author. e-mail: hjyao@ustc.edu.cn

(c) The Seismological Society of China, Institute of Geophysics,

China Earthquake Administration, and Springer-Verlag Berlin Heidelberg 2012
}

(Zhang et al., 2004; Royden et al., 2008), and (4) many active faults and numerous intra-continental earthquakes (Engdahl et al., 1998) inside the plateau and around the plateau margin (Figure 1), including the devastating Wenchuan earthquake $\left(M_{\mathrm{S}} 8.0\right)$ of 12 May 2008 in the Longmenshan fault zone of the eastern Tibetan plateau margin (Figure 1; Burchfiel et al., 2008; Zhang et al., 2010).

A number of mechanisms have been proposed to explain the formation and deformation patterns of the Tibetan plateau, including the two popular and competing end-member models: rigid block extrusion (Tapponnier et al., 1982, 2001) and crustal channel flow (Royden et al., 1997, 2008; Clark and Royden, 2000; Beaumont et al., 2001). Models of rigid block extrusion suggest that the rigid Tibetan lithosphere has been extruded from central plateau along some major strike-slip faults due to the indention of India into Asia. The dominant deformation mode of this extrusion tectonics is faulting, and the crust and upper mantle experience vertically 
coherent deformation. Models of crustal channel flow, however, suggest that there exists a low viscosity (i.e., mechanically weaker) mid-lower crustal channel where (ductile) crustal material can be more efficiently transported to SW China and NE Tibet from the central plateau. Due to the existence of this weak mid-lower crustal layer, the deformation in the upper crust and upper mantle is largely decoupled. When these models were proposed about $15-30$ years ago, the detailed 3-D lithospheric structure beneath the Tibetan plateau was still unclear primarily due to the lack of dense coverage of seismic stations or other geophysical observations in the Tibetan plateau. Each of these two end-member models can only explain part of the topographic, geologic, tectonic, and geophysical observations, which reflects complexities of the physical structure of the Tibetan plateau and its dynamic evolution in the geological history.

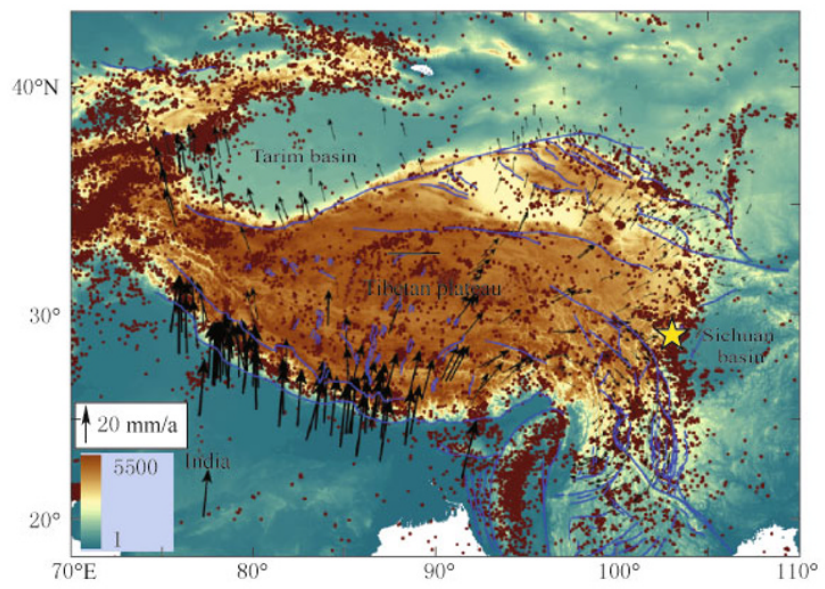

Figure 1 Topography, seismicity, fault systems, and surface motion of the Tibetan plateau and its adjacent regions. Colorbar means topographic height (m); dots denote earthquakes with $M>4$ in the years 1960-2007 from EHB catalogue (Engdahl et al., 1998); yellow star denotes hypocenter of the 2008 Wenchuan earthquake; blue lines denote fault systems; black arrows denote GPS velocity fields (Zhang et al., 2004; Sol et al., 2007) with respect to the South China block.

In the southeastern Tibetan plateau, there exist a number of tectonic units separated by major suture zones or large strike-slip fault systems (Figure 2). Deformation of this region is mainly influenced by northward subduction of the Indian plate along the Indus-Tsangpo suture (Yin and Harrison, 2000), eastward subduction of the Myanmar microplate along the Myanmar arc (Ni et al., 1989; Li et al., 2008), and resistance to further eastward expansion of the Tibetan plateau by the (mechanically) rigid Sichuan basin (e.g., Cook and Royden,
2008). GPS analysis (Zhang et al., 2004) confirmed that the surface (or the rigid upper crust) material in southern or central Tibet has been clockwise transported to SW China (Figure 1). However, how the deeper crust and upper mantle material was transported or deformed is still not very clear.

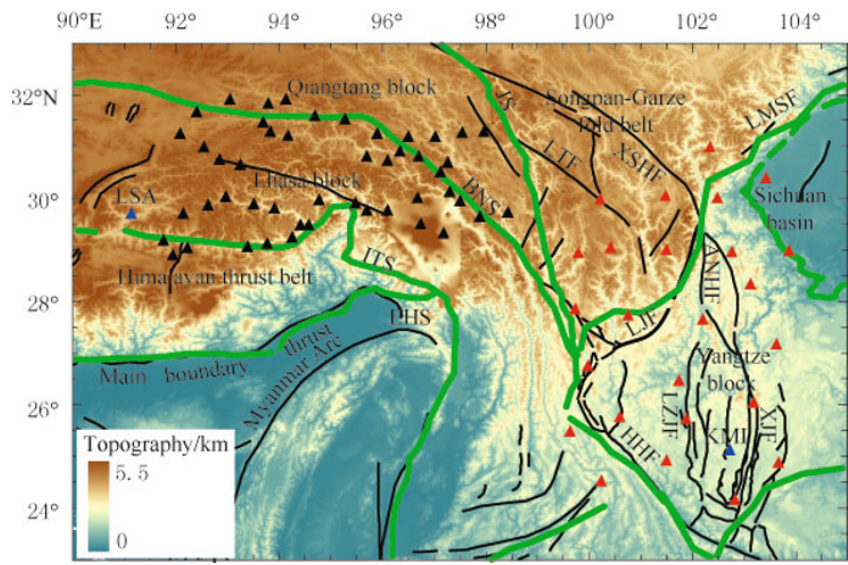

Figure 2 Topography, tectonic elements and fault systems in the southeastern part of the Tibetan plateau around the eastern Himalayan syntaxis (EHS). Green lines stand for tectonic boundaries, black lines for fault systems, red and black triangles for temporary array stations deployed by MIT and Lehigh University in 2003-2004 respectively, and blue triangles for two permanent stations located at Lhasa (LSA) and Kunming (KMI). Abbreviations are as follows: JS, Jinsha suture; BNS, Bangong-Nujiang suture; ITS, Indus-Tsangpo suture; LMSF, Longmenshan fault; XSHF, Xianshuihe fault; LTF, Litang fault; ANHF, Anninghe fault; LJF, Lijiang fault; LZJF, Lüzhijiang fault; XJF, Xiaojiang fault; HHF, Honghe fault.

In the past ten years, dense portable seismic arrays in SE Tibet as well as advances in seismic tomographic methods, in particular ambient noise tomography (e.g., Shapiro et al., 2005; Yao et al., 2006), have fundamentally revealed the 3-D (isotropic and anisotropic) structure in the crust and upper mantle beneath SE Tibet (Lev et al., 2006; Yao et al., 2006, 2008, 2010; Sol et al., 2007; Xu et al., 2007; Li et al., 2009, 2010a; Liu et al., 2009; Zhang et al., 2009; Huang et al., 2010; Li et al., 2010b; Wang et al., 2010; Zheng et al., 2010; Yang et al., 2012). Together with other geophysical observations in this area, for instance, surface heat flow (Hu et al., 2000), gravity anomalies and effective elastic thickness (Jordan and Watts, 2005), and magnetotelluric imaging (Bai et al., 2010), we now have a much better understanding of the lithospheric structure and deformation patterns in SE Tibet. 
In this review paper, I first give a brief overview of ambient noise and earthquake surface wave tomography, then summarize the major findings in the lithospheric structure and deformation in SE Tibet revealed by ambient noise and earthquake surface wave tomography as well as by other seismic and geophysical observations, and finally discuss some future perspective researches.

\section{Ambient noise and earthquake surface wave tomography}

In this section I will first give a brief overview about ambient noise tomography and earthquake surface wave tomography using two-station analysis. Then I will introduce the scheme of joint ambient noise and earthquake surface wave tomography (Yao et al., 2008) for better constraining crust and upper mantle structures.

\subsection{Ambient noise tomography}

Since the pioneer work of Shapiro and Campillo (2004) and Shapiro et al. (2005), ambient noise tomography has become one of the most important tomographic methods in structural seismology to understand the crustal structure (e.g., Sabra et al., 2005; Yao et al., 2006; Yang et al., 2007; Lin et al., 2008). By crosscorrelating long-time series (e.g., one year) of ambient noise signals between pairs of seismic stations, we can recover surface wave Green's function (SWGF) in the short and intermediate period bands (e.g., 5-40 s) between station pairs, which then can be used to image 3-D structures of the Earth, in particular the crust, in regions with dense seismic stations. Since this method does not need to use earthquake signals, it allows for high-resolution crustal tomography in regions without seismicity. Compared to high-resolution crustal imaging using active source (e.g., reflection or refraction) methods, ambient noise tomography has much lower cost and will not cause environmental issues. Due to these advantages, ambient noise tomography has become a routine and efficient imaging method in array seismology.

The processing of ambient noise data usually requires temporal or spectral normalization (e.g., Bensen et al., 2007) in order to suppress large transient signals from earthquakes or other sources and to enhance weak and almost continuous ambient noise signals for the recovery of SWGFs. Here, I denote the recovered SWGFs as empirical Green's functions (EGFs), which is equivalent to the time-derivative or Hilbert transform of ambient noise cross-correlation functions (e.g., Yao et al., 2011). In theory, perfect recovery of the Green's func- tion requires isotropic distribution of noise sources (e.g., Snieder, 2004). In practice, the distribution of ambient noise sources (e.g., from microseisms) is inhomogeneous and has clear seasonal variations. The uneven distribution of ambient noise sources may bias the recovery of SWGFs. However, this bias in travel times or dispersion measurements is usually small (mostly less than 1\%) if the noise power only has smooth azimuthal variations (Yao and van der Hilst, 2009), which can be nearly satisfied if we perform careful temporal and spectral normalization and average over about one year data. This ensures the quality and reliability of ambient noise tomography.

Cross-correlation of the vertical (or radial) component ambient noise data gives inter-station Rayleigh wave EGFs (Shapiro and Campillo, 2004), while crosscorrelation of the transverse component data yields Love wave EGFs (Lin et al., 2008). Typically, we first measure inter-station group (Shapiro and Campillo, 2004) or phase (Yao et al., 2006) velocity dispersion curves from the obtained EGFs, then construct perioddependent 2-D group or phase velocity maps using all inter-station dispersion measurements (Shapiro et al., 2005; Yao et al., 2006), and finally invert for 3-D shear velocity structures.

The most successful period range for SWGF recovery and dispersion measurements is about 5-40 s (e.g., Yao et al., 2006, 2010; Yang et al., 2007; Lin et al., 2008), which mainly constrains crust structures. For closely spaced stations (e.g., about $10 \mathrm{~km}$ or less), very short-period EGFs (e.g., at several seconds period) can also be retrieved ( $\mathrm{Li}$ et al., 2010b), which provides important constraints on very shallow crust or near surface velocity structures. Measurements of phase velocities from EGFs appear more stable and robust (Yao et al., 2006) than group velocities in particular above 20 s period (Bensen et al., 2008). This is probably due to larger uncertainty in determining the peak of the envelope function for group velocity measurements. Measurements of phase velocity dispersion curves at shorter periods (e.g., less than $15 \mathrm{~s}$ ) are usually difficult due to cycle skipping problems. However, the dispersion curve can be tracked from longer periods to shorter periods to prevent such ambiguities, e.g., using a phase-velocity image analysis technique (Yao et al., 2006).

\subsection{Earthquake surface wave tomography from two-station analysis}

Earthquake surface waves have been widely used to study the regional and global upper mantle structure of the Earth. For teleseismic surface waves, most 
short period (e.g., less than 15 s period) energy has been attenuated along the ray path. And complicated wave propagation phenomena, such as scattering and multipathing, will also make shorter periods surface wave unreliable for tomographic purposes. Therefore, earthquake surface waves are usually difficult to constrain the crustal shear velocity structure.

Earthquake surface wave tomography from dispersion measurements or waveform inversion using a single station method requires information of earthquakes, such as origin times, locations, and focal mechanisms, which are usually not accurately known. Biases in these source parameters will result in errors in tomographic images. Another classic approach, called two-station (TS) analysis (e.g., Landisman et al., 1969; Yao et al., 2005), determines the relative phase travel times or average phase velocities between two stations almost along the same great circle path from an earthquake to the two stations. This approach is more accurate in measuring inter-station phase velocities because it can almost remove uncertainties in source parameters and also the effect of structural heterogeneity from the earthquake to the closer station. Typically, TS analysis can be used to measure inter-station phase velocities in the intermediate and long period bands, e.g., between 20-150 s, which can constrain the shear velocity structure in a depth range about $25-250 \mathrm{~km}$. By combining all phase velocity measurements from different inter-station paths, 2-D phase velocity maps can be constructed and then $3-\mathrm{D}$ upper mantle shear velocity structure can be obtained via pointwise inversion.

\subsection{Joint ambient noise and earthquake surface wave tomography}

Since inter-station phase velocity dispersion curves can be measured from both ambient noise analysis (mainly in the period band 5-40 s) and TS analysis of earthquake surface waves (mainly in the period band $20-150 \mathrm{~s}$ ), it is straightforward to compare the phase velocities at the overlapping periods (e.g., 20-40 s) from both methods and access the reliability of both measurements. In SE Tibet, the inter-station phase velocities from these two methods are quite similar (with standard deviations less than $1.5 \%$ ) at the overlapping periods of 20-40 s for most station pairs (Yao et al., 2008, 2010). However, above $40 \mathrm{~s}$ period, their differences become much larger with standard deviations about $2.5 \%$ at $50 \mathrm{~s}$ (Yao et al., 2010). This large difference may be due to lower signal to noise ratio (SNR) in recovery of SWGFs above $40 \mathrm{~s}$ period from ambient noise (e.g., Bensen et al., 2008), different sensitivity kernels of phase velocity measurements from ambient noise and earthquake-based methods, and finite frequency effects of surface wave propagation at longer periods, in particular in the tectonically complicated SE Tibet.

Some other studies have successfully performed ambient noise tomography at much longer periods, e.g., up to $60 \mathrm{~s}$ in China (Zheng et al., 2008; Sun et al., 2010), up to $70 \mathrm{~s}$ in the US (Bensen et al., 2008), and in the Earth's hum period band (100-400 s) in a global scale (Nishida et al., 2009). Shen et al. (2012) provided an improved method for ambient noise analysis, which improves the SNR of the recovered surface waves and can efficiently extract very-broadband SWGFs from ambient noise. However, at long periods there still lacks direct comparison between the interstation dispersion measurements from ambient noise and those from earthquake-based methods although the tomographic images appear to be similar from different approaches (Nishida et al., 2009).

The similarity of phase velocity dispersion at the overlapping periods from these two methods in SE Tibet results in joint ambient noise and earthquake surface wave tomography (Yao et al., 2008, 2010). The joint tomographic scheme is summarized in Figure 3. The combination and averaging of phase velocity measurements from both methods for each two-station path (Yao et al., 2008) have two advantages, that is, increase of the number of ray paths (Yao et al., 2008, 2010) and suppression of errors in phase velocity measurements from both methods in the overlapping periods. Therefore, the proposed dispersion average scheme has the potential to increase lateral resolution and reliability of the constructed phase velocity maps at the overlapping periods.

Another joint ambient noise and earthquake surface wave tomography approach, proposed by Yang et al. (2008), directly combines phase velocity maps at shorter periods (below $40 \mathrm{~s}$ period) from ambient noise tomography and at longer periods (above $40 \mathrm{~s}$ period) from the two-plane phase velocity tomography using teleseismic surface waves to invert for $3-\mathrm{D}$ shear velocity structures. Therefore, it does not have the advantages in the above joint method (Figure 3) that averages the dispersion curves from both methods. 


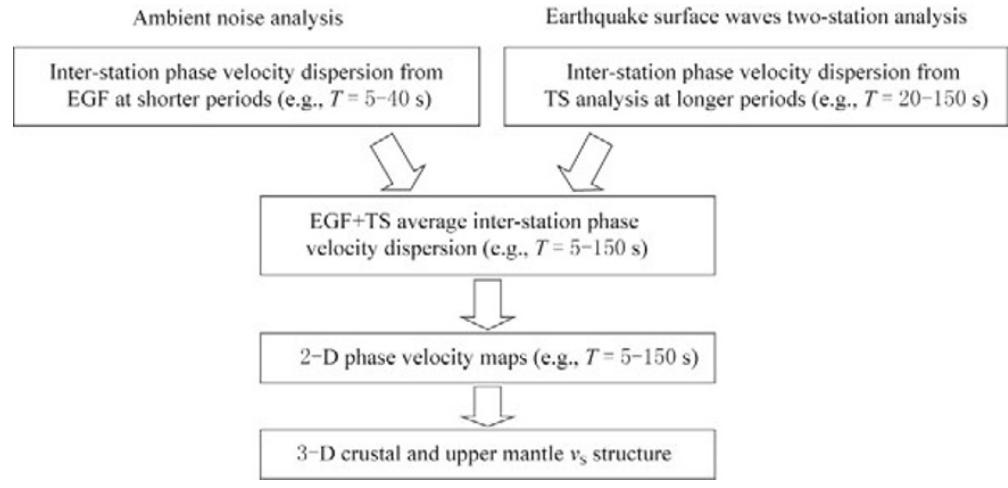

Figure 3 Scheme of joint ambient noise and earthquake surface wave tomography (Yao et al., 2008).

\section{Lithospheric structure and de- formation in SE Tibet}

In the past few years, seismic tomography from ambient noise and earthquake surface waves has greatly improved our understanding of the (isotropic and anisotropic) structure in the crust and upper mantle beneath SE Tibet and its adjacent regions. Yao et al. (2008) used the joint ambient noise and earthquake surface wave tomography (Figure 3) to infer the lithospheric shear velocity $\left(v_{\mathrm{SV}}\right)$ structure in the southeastern margin of the Tibetan plateau (in western Sichuan and northern Yunnan) using the vertical-component data from the MIT-China array (Figure 2). Using ambient noise tomography with data from about 50 provincial array stations in Sichuan, Li et al. (2009, 2010a) obtained the crustal $v_{\mathrm{SV}}$ structure and radial anisotropy of the Sichuan province, respectively. Huang et al. (2010) obtained the shear wave radial anisotropy in the crust of the southeastern margin of the Tibetan plateau using three-component ambient noise data from the MITChina array. Yao et al. (2010) combined ambient noise and earthquake surface wave data from the MIT-China array and Lehigh array to invert for the $v_{\mathrm{SV}}$ structure and its azimuthal anisotropy in the lithosphere of SE Tibet. Zheng et al. (2010) obtained a crustal model in eastern Tibet, Sichuan basin, and Ordos basin from ambient noise tomography with data from about 150 provincial array stations. Li et al. (2010b) obtained very high-resolution phase velocity maps in the period band 2-40 s from ambient noise tomography with data from the dense array in western Sichuan (about 300 stations). Yang et al. (2012) used ambient noise data from about 600 stations in the Tibetan plateau and its adjacent regions to obtain the crustal $v_{\mathrm{SV}}$ structure beneath the Tibetan plateau. Here I will summarize the main to- mographic results in SE Tibet from ambient noise and earthquake surface wave tomography, in particular the distribution of crustal low velocity zones and seismic anisotropy. Together with constraints from other seismic and geophysical results, I will discuss the lithospheric deformation patterns in SE Tibet.

\subsection{Distribution of crustal low velocity zones}

There exist widespread low velocity zones (LVZs) in the mid-lower crust beneath SE Tibet (see Figures 4 and 5 for examples) (Yao et al., 2008, 2010; Li et al., 2009; Zheng et al., 2010; Yang et al., 2012). Even at $40 \mathrm{~km}$ depth, there still exists a broad region with shear wave speeds lower than $3.4 \mathrm{~km} / \mathrm{s}$ (Figure 4b), which probably indicates partial melting of deep crustal rocks due to high temperatures (e.g., Yang et al., 2012). This is consistent with high surface heat flow values in SE Tibet (Hu et al., 2000), implying elevated geotherm at depths. The existence of partial melt at mid-lower crustal depths in SE Tibet is consistent with observations of high Poisson's ratio from receiver function studies (Xu et al., 2007; Liu et al., 2009; Zhang et al., 2009; Wang et al., 2010) and high conductivity from magnetotelluric imaging (Bai et al., 2010) in the crust of SE Tibet. The existence of partial melt in the deep crust will significantly decrease crustal rigidity (or viscosity), consistent with very low effective elastic thickness (about 0-20 km) in SE Tibet (Jordan and Watts, 2005). All these results are consistent with models of channel flow in the mechanically weak mid-lower crust (Royden et al., 1997; Clark and Royden, 2000; Cook and Royden, 2008).

Although the distribution of mid-lower crustal LVZs seems ubiquitous in SE Tibet, the 3-D geometry and connectivity of these LVZs are quite complicated (see Figure 5 for examples) (e.g., Yao et al., 2008, 2010; Huang et al., 2010; Yang et al., 2012). There are two main features of the crustal LVZs. First, the crustal 
LVZs have apparent depth variations in different tectonic units. For instance, in the Lhasa block (north of latitude $28^{\circ} \mathrm{N}$; Figure $5 \mathrm{a}$ ), LVZs only appear in the middle crust and the lower crust has high wave speeds. However, in the Qiangtang block and Songpan-Garze fold belt, LVZs may exist in both the middle crust and lower crust (Figure 5). In SW China, apparent LVZs appear in the middle crust beneath the Xiaojiang fault zone (Figure 5b; Yao et al., 2008, 2010). Second, the lateral boundaries of LVZs in SE Tibet may coincide roughly with some major fault zones in this area (Yao et al., 2008, 2010; Li et al., 2009; Liu et al., 2009). For instance, a clear mid-crustal LVZ is observed northwest of the Longmenshan fault zone by both ambient noise tomography (Li et al., 2009) and receiver function imag- ing (Liu et al., 2009). The hypocenter of the 12 May 2008 Wenchuan earthquake is just located above the eastern edge of this mid-crustal LVZ (Li et al., 2009). The cause of this earthquake is still under debate, for instance, by the uplift of the low-viscosity mid-lower crustal material due to ductile thickening of the deep crust as the result of channel flow in eastern Tibet (Burchfiel et al., 2008) or brittle crustal thickening, in which thrust faults with large amounts of slip that are rooted in the lithosphere cause uplift (Hubbard and Shaw, 2009). The mid-crustal LVZ in the SongpanGarze fold belt disappears around the Xianshuihe fault zone (Figure 5a; Yao et al., 2008, 2010). Magnetotelluric imaging (Bai et al., 2010) also similarly shows that the Xianshuihe fault zone seems to be the eastern boundary
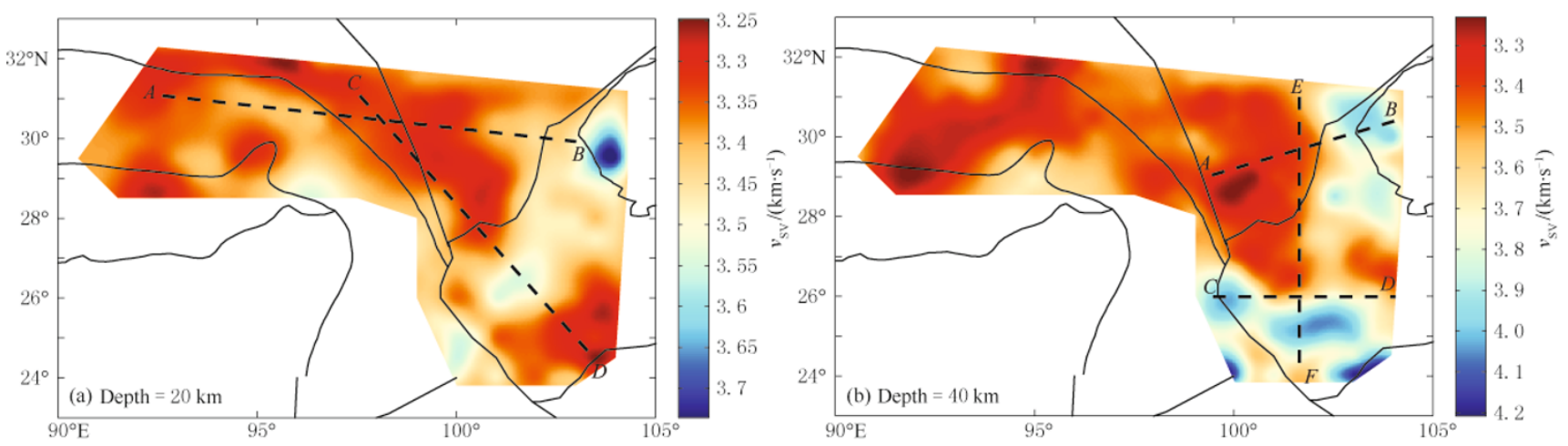

Figure 4 Shear wave speeds ( $\left.v_{\mathrm{SV}}\right)$ at $20 \mathrm{~km}$ (a) and $40 \mathrm{~km}$ (b) depths in SE Tibet obtained by joint ambient noise and earthquake surface wave tomography (Yao et al., 2010). In (a) and (b), the dashed lines show the location of vertical shear wave speed profiles in Figures 5 and 6, respectively.
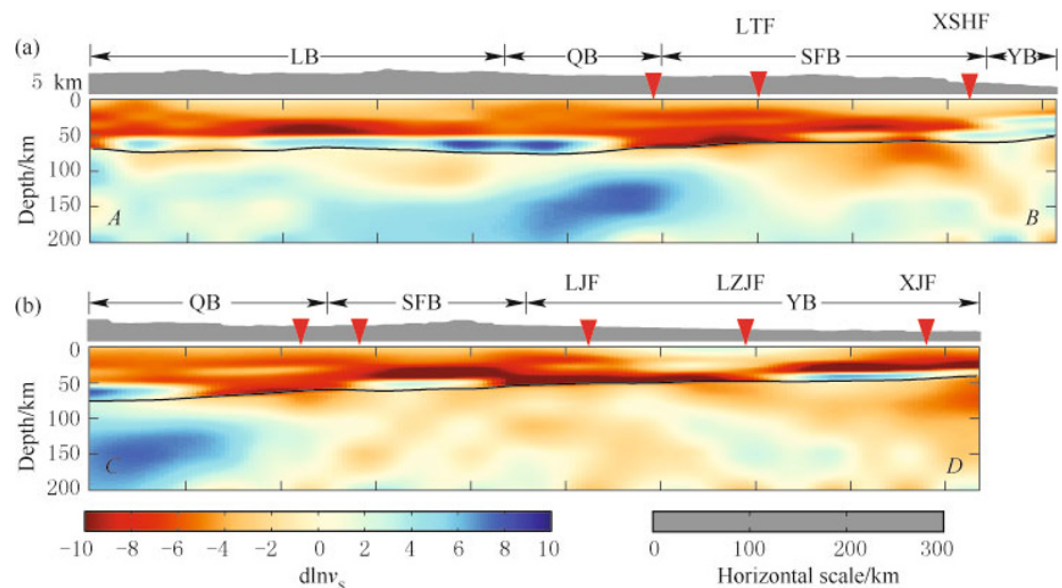

Figure 5 Perturbation of shear wave speeds $\left(v_{\mathrm{SV}}\right)$ with respect to the reference model along the two profiles in Figure 4a (modified from Yao et al., 2010). The reference $v_{\mathrm{SV}}$ linearly increases from $3.4 \mathrm{~km} / \mathrm{s}$ at the surface to $3.85 \mathrm{~km} / \mathrm{s}$ at the Moho depth (black line); in the upper mantle, the reference $v_{\mathrm{SV}}$ is from the global ak135 model (Kennett et al., 1995). Red triangles and black vertical lines denote location of major faults and tectonic unit boundaries along each profile, respectively. The abbreviations for fault names are the same as in Figure 2. The abbreviations for the tectonic units are as follows: LB, Lhasa block; QB, Qiangtang block; SFB, Songpan-Garze fold belt; YB, Yangtze block. 
of the high-conductivity zones in the middle crust beneath SE Tibet. The Lüzhijiang fault seems to be the western boundary of the mid-crustal LVZ beneath the Xiaojiang fault zone (Figure 5b; Yao et al., 2008, 2010). If channel flow does exist in the deep crust of SE Tibet, we expect that the flow pattern will be quite complicated due to strong variations in the 3-D geometry of LVZs as well as their possible interplay with major fault zones.

\subsection{Radial and azimuthal anisotropy in the lithosphere}

Seismic anisotropy is mainly caused by shape or lattice preferred orientation of minerals in the Earth (Savage, 1999) and it could preserve the information of accumulated deformation in the geological history. Large positive radial anisotropy $\left(v_{\mathrm{SH}}>v_{\mathrm{SV}}\right)$ in the midlower crust of the southeastern margin of the Tibetan plateau (Figure 6) is observed from ambient noise tomography (Huang et al., 2010; Li et al., 2010a). However, in the upper crust, the magnitude of radial anisotropy is very small. This implies sub-horizontal alignment of anisotropic crustal minerals, such as mica, mainly in the deep crust. In particular, large positive radial anisotropy is spatially correlated with LVZs in the mid-lower crust of SE Tibet (Figure 6; Huang et al., 2010; Li et al., 2010a). This feature is generally consistent with near horizontal flow or shear deformation of crustal material in the mechanically weak zones of deep crust in SE Tibet.

Joint ambient noise and earthquake surface wave tomography reveals apparent differences in crust and upper mantle azimuthal anisotropy of shear velocities beneath SE Tibet (Yao et al., 2010). In the upper crust (e.g., at $10 \mathrm{~km}$ depth, Figure 7), the fast polarization directions of $v_{\mathrm{SV}}$ show a prominent curvilinear pattern around the eastern Himalayan syntaxis, similar to the pattern of surface motion from GPS (Figure 1; Zhang et al., 2004). In particular, in the Chuan-Dian area, the fast polarization axes are nearly parallel to the orientation of some major fault zones, such as the XianshuiheXiaojiang fault zone. This is an indication of simple shear deformation in the upper (rigid) crust, probably controlled by strike-slip faulting in the shallower crust. However, the fast polarization axes of $v_{\mathrm{SV}}$ in the upper mantle (e.g., at $100 \mathrm{~km}$ depth, Figure 7) clearly differ from those in the upper crust. In the Chuan-Dian area, the fast polarization axes appear to align along the western margin of the Yangtze block, approximately following the orientations of the Lijiang and Honghe faults. The depth variations in azimuthal anisotropy of $v_{\mathrm{SV}}$ in the crust and upper mantle (Yao et al., 2010) may indicate differences in patterns of deformation in the crust and upper mantle beneath SE Tibet.
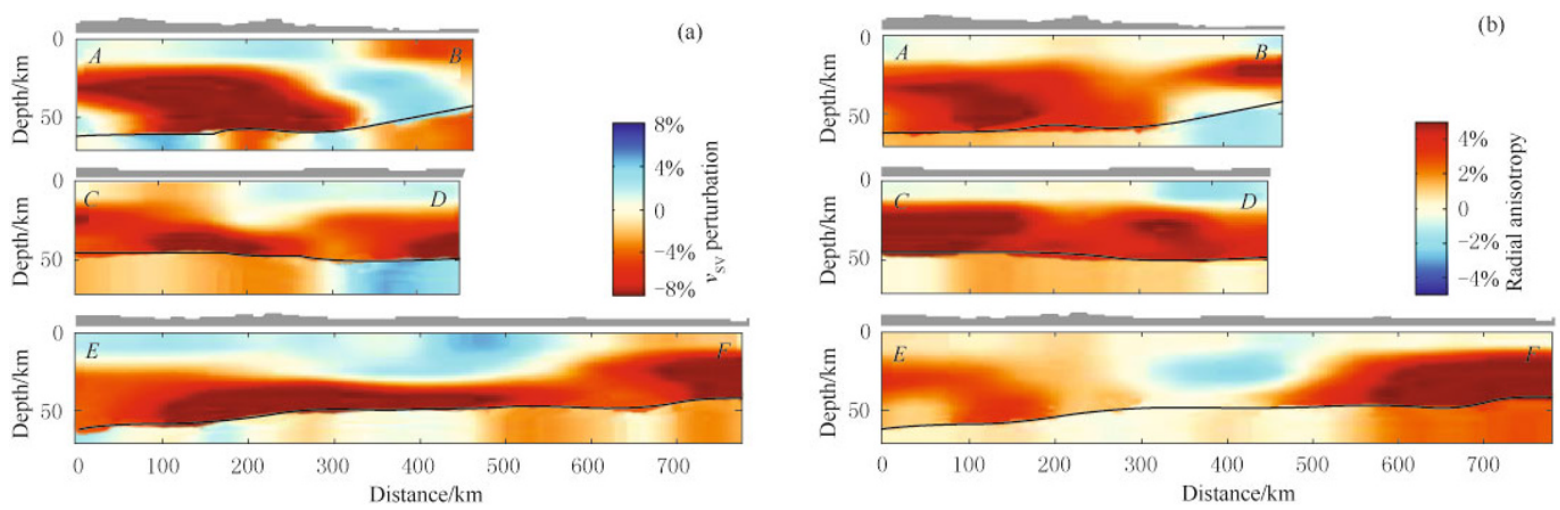

Figure 6 Shear wave speed $\left(v_{\mathrm{SV}}\right)$ perturbation (a) and the corresponding radial anisotropy $\left(2\left(v_{\mathrm{SH}}-v_{\mathrm{SV}}\right) /\left(v_{\mathrm{SH}}+v_{\mathrm{SV}}\right)\right)$ in the crust (b) along the three profiles in Figure $4 \mathrm{~b}$ obtained from ambient noise Rayleigh and Love waves tomography (modified from Huang et al., 2010). The black line shows the Moho interface.

\subsection{Lithospheric deformation patterns in SE Tibet}

Various geophysical observations have implied that channel flow probably exists in the (mechanically weak) mid-lower crust beneath SE Tibet, including ubiquitous distribution of mid-lower crustal LVZs, spatial correlation of large positive radial anisotropy $\left(v_{\mathrm{SH}}>v_{\mathrm{SV}}\right)$ with deep crustal LVZs, high-conductivity mid-crustal channels, high Poisson's ratio in the crust, high surface heat flow values, as well as very low effective elastic thickness. However, it is still not very clear whether the existence of such weak channel in the mid-lower crust may decouple the surface motion (or deformation) from that in the upper mantle in SE Tibet. Crustal channel flow mod- 
els suggest decoupling between the upper crust and upper mantle lithosphere (e.g., Royden et al., 1997, 2008), while models of block extrusion imply vertically coherent deformation in the crust and upper mantle (e.g., Tapponnier et al., 1982, 2001).

Similar patterns exist between the instantaneous surface strain field from GPS and azimuthal anisotropy from shear wave splitting (Figure 8), suggesting that the crust and upper mantle may be mechanically coupled or vertically coherently deformed in Tibet (e.g., Flesch et al., 2005; Sol et al., 2007; Wang et al., 2008). However, this comparison may have uncertainties in the explanation of crust-mantle deformation patterns due to two reasons:

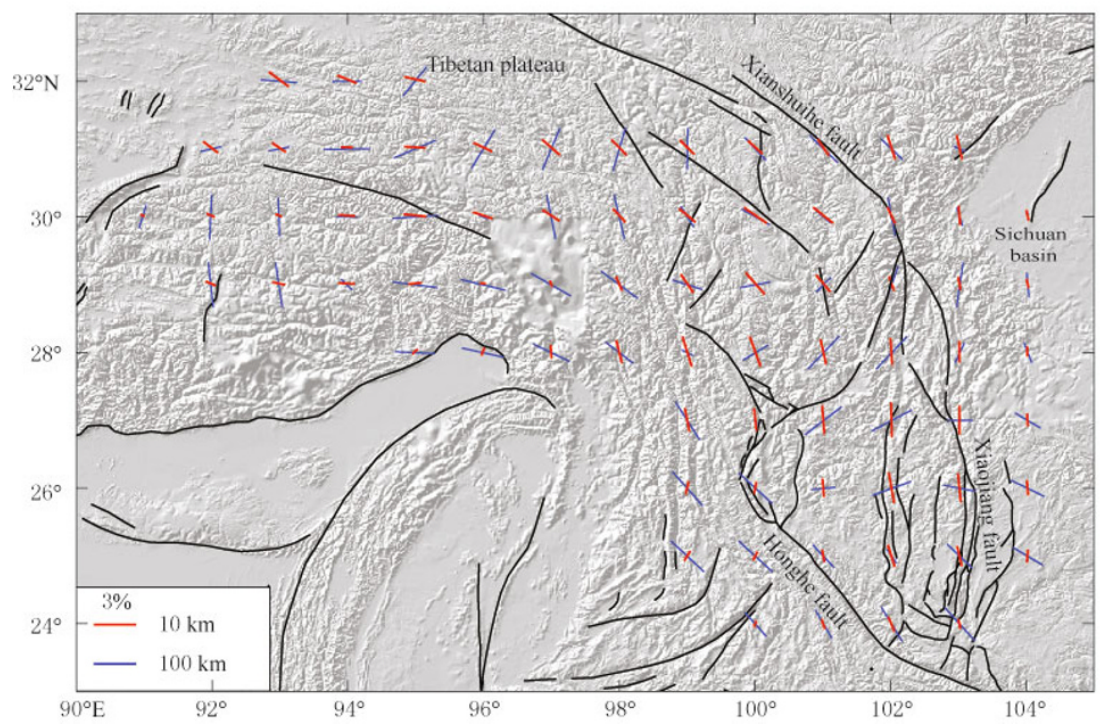

Figure 7 Observed shear wave azimuthal anisotropy at $10 \mathrm{~km}$ (red bars) and $100 \mathrm{~km}$ (blue bars) depths from joint ambient noise and earthquake surface wave tomography (Yao et al., 2010). The black lines show the fault systems.

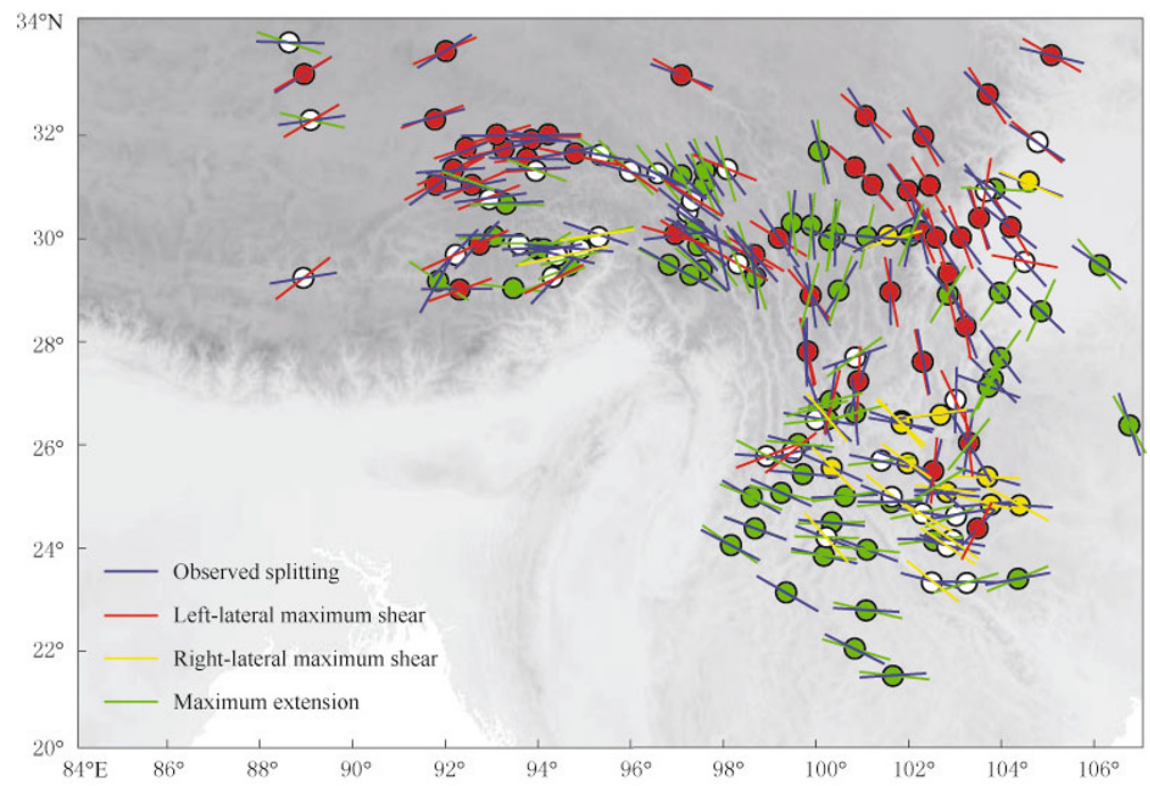

Figure 8 Comparison of the fast directions of shear wave splitting measurements (blue lines) and the maximum surface deformation directions from GPS measurements (red, yellow, and green lines) in SE Tibet (modified from Figure 2 in Wang et al., 2008). 
(1) the instantaneous surface strain field from GPS may be not appropriate to represent the accumulated strain in the entire crust over the geological history considering the complicated tectonic history and possible depth variations in the crustal strain field in SE Tibet; and (2) patterns of azimuthal anisotropy from shear wave splitting usually lack depth resolution and it is sometimes risky to use shear wave splitting observations to represent upper mantle anisotropy or deformation. In particular in SE Tibet, the crust contribution to shear wave splitting cannot be ignored due to very thick and also highly deformed crust (Yao et al., 2010). In the future, the integration of shear wave splitting measurements from local and teleseismic events may help to better constrain the depth-dependent azimuthal anisotropy in the lithosphere of SE Tibet.

Azimuthal anisotropy from surface waves provides much better constraints on depth-dependent deformation in the lithosphere. In Tibet, azimuthal anisotropy from Rayleigh-wave group velocity tomography indicates a coherent pattern within the crust and lithospheric mantle (Su et al., 2008). However, inter-station phase velocity tomography observes apparent differences in fast directions of Rayleigh-wave propagation from intermediate to long periods in Tibet, suggesting different deformation styles in crust and upper mantle (Yi et al., 2010). The lateral resolution of these two controversial results is about $400-500 \mathrm{~km}$. The regional surface-wave array tomography from ambient noise and earthquake data reveals apparent depth variations in azimuthal anisotropy in SE Tibet with lateral resolution about $200 \mathrm{~km}$ (Yao et al., 2010), suggesting that the crust and upper mantle in SE Tibet, at least regionally, are likely to have different deformation patterns. This is probably due to the existence of mechanically weak layer in the mid-lower crust in SE Tibet as the results of high temperature and partial melting. However, the spatial extent and degree of decoupling between crust and upper mantle in SE Tibet is still not well understood.

The mid-lower crustal LVZs or high-conductivity zones beneath SE Tibet are not homogenously distributed but show complicated 3 -D geometries in various tomographic or imaging results. Therefore, the mechanical properties (e.g., viscosity) in the crust may show lateral and vertical variations as well. This implies that the pattern of crustal channel flow will be more complicated than that predicted by previous crustal channel flow models that assume simple depthdependent viscosity profiles (e.g., Royden et al., 1997;
Cook and Royden, 2008). Also, the connectivity of these crustal LVZs may strongly depend on regional structures, e.g., the distribution of major fault zones. Although how deep these faults can penetrate in the lithosphere is still not well resolved by current tomographic results, some faults do seem to behave as a boundary or barrier of some LVZs at mid-crustal depths. Results of azimuthal anisotropy indicate that the upper crustal deformation in the Chuan-Dian area appears to be mainly controlled by strike-slip faulting, in agreement with models of rigid block extrusion (Tapponnier et al., 1982). The interplay between major faults and weak zones in the deep crust is probably another important deformation mechanism in SE Tibet.

In summary, current geophysical observations agree on the existence of mechanically weak zones (with complicated 3-D geometries) in the mid-lower crust of SE Tibet and there exist apparent differences in deformation patterns between crust and upper mantle beneath SE Tibet. These results are consistent with models of deep crustal channel flow in SE Tibet. Current results also indicate the importance of (strike-slip) faulting in the deformation history of SE Tibet at upper and middle crustal depths, partially in agreement with the rigid block extrusion model. Therefore, integration of block extrusion in the more rigid upper-middle crust and channel flow in the more ductile mid-lower crust will be more compatible with current geophysical observations. However, such integration is not simple and probably has strong lateral variations.

\subsection{Future perspective research in SE Tibet}

Current seismic and other geophysical observations have provided important constraints on the structure and deformation patterns in the lithosphere of SE Tibet. However, the spatial or vertical resolution is still limited by data coverage and methodologies. For instance, ambient noise tomography using data from the MIT-China array, Lehigh array, and provincial arrays in SW China only has lateral resolution about $50-100 \mathrm{~km}$ in the crust (e.g., Yao et al., 2008, 2010; Li et al., 2009; Zheng et al., 2010), which is not sufficient to resolve fault zone structures. This situation can be improved by recent progresses in the deployment of very dense portable arrays in SW China, e.g., the nearly 300-station array in western Sichuan deployed in 2007-2009 by Institute of Geology, China Earthquake Administration (CEA) (Liu et al., 2009), and another dense array (over 300 hundred stations) in Yunnan deployed in 2011 by Institute of Geophysics, CEA. The station spacing of these dense arrays is about $10-30 \mathrm{~km}$, which can provide more de- 
tailed structures in SW China, for instance, structures of major fault zones and deep crustal LVZs.

In many cases the tomographic or imaging resolution depends not only on data coverage but also on methods. For seismic tomography, proper incorporation of better theories in wave propagation (e.g., ray bending, focusing and defocusing, 3-D finite frequency kernels) can help to improve the reliability and resolution of tomographic models. A number of new array tomographic methods have been developed for ambient noise and earthquake surface wave tomography in recent years, including the Eikonal tomography (Lin et al., 2009) and Helmholtz tomography (Lin et al., 2011). Adjoint tomography using ambient noise data is another promising direction (Chen et al., 2010), however, typically with very high computational cost. Also 3-D sensitivity kernels of traveltimes from ambient noise crosscorrelation (Tromp et al., 2010) may strongly depend on the distribution of ambient noise sources, which is usually poorly known. Anyway, together with the newly deployed dense array stations, these new array techniques using ambient noise and earthquake surface waves will provide more accurate information of the velocity structures in SE Tibet. It is also likely that the 3-D attenuation structure in the crust and upper mantle can be resolved using array-based methods of ambient noise (Prieto et al., 2009) and earthquake surface waves (Lin et al., 2012a). This will provide other important constraints on the distribution of crustal weak zones in SE Tibet.

Due to differences in data coverage and sensitivity to structure using different seismic data (e.g., body wave traveltimes, surface wave dispersion, receiver functions), the obtained velocity structure from different methods may have apparent discrepancies. For instance, clear differences exist in the 3-D geometry of the crustal low velocity zones by ambient noise tomography (e.g., Yao et al., 2010; Yang et al., 2012) and body wave traveltime tomography (e.g, Huang et al., 2002; Wang et al., 2003; Huang et al., 2009). Joint inversion of multiple seismic data may help to provide more consistent structural results. In western Sichuan, joint inversion of receiver functions and Rayleigh wave dispersion data from ambient noise cross-correlation can better constrain the crustal shear velocity structure and interfaces than using only one dataset (Liu et al., 2010). Joint inversion of Rayleigh wave dispersion and ellipticity data (amplitude ratio between the vertical and radial components of Rayleigh waves) may provide better constraints on velocity and density structure in the upper crust (e.g., in western U.S., by Lin et al., 2012b). Joint inversion of S wave traveltime data and Rayleigh wave dispersion data from ambient noise cross-correlation appears to better constrain the crustal LVZs in SW China (Zhang et al., 2011). Therefore, compared to inversion only from a single dataset, joint inversion of multiple seismic observations from current dense array stations in SE Tibet can provide better constraints on the velocity $\left(v_{\mathrm{P}}, v_{\mathrm{S}}\right.$, and $\left.v_{\mathrm{P}} / v_{\mathrm{S}}\right)$ and density structure in the crust of SE Tibet.

The development of new array tomographic methods and joint inversion schemes as well as current dense seismic array observations in SE Tibet will greatly enhance the resolution and accuracy of the crust and upper mantle model in SE Tibet, which will help to improve our understanding about current physical states as well as historical deformation (e.g., from seismic anisotropy) in the lithosphere of SE Tibet. An important but very challenging study is how these geophysical observations can help to constrain the dynamic evolution and lithospheric deformation patterns of SE Tibet or the entire Tibetan plateau. This may involve proper incorporation of high-resolution seismic and other geophysical imaging results, for instance, the distribution of the major fault zones and deep crustal weak zones, into more realistic geodynamic models. These models will be essential to constrain the spatial extent and degree of coupling/decoupling between crust and mantle in SE Tibet. How geodynamic modeling is used to understand seismicity and seismo-tectonics in SE Tibet, for instance, distribution and mechanisms of devastating crustal earthquakes, is another challenging research topic.

\section{Summary}

In this review paper, I first give a brief overview about ambient noise and earthquake surface wave tomography. Then I summarize the main results of the lithospheric structure and deformation patterns beneath SE Tibet from ambient noise and earthquake surface wave tomography as well as from other seismic and geophysical methods. Results from various geophysical studies agree on the existence of mechanically weak zones in the mid-lower crust beneath SE Tibet, which is generally consistent with models of mid-lower crustal channel flow. However, the 3-D pattern of channel flow may be complicated as inferred from strong lateral and radial variations in $3-\mathrm{D}$ geometries of crustal weak zones.

The crust-mantle deformation pattern is still un- 
der debate. Tomographic results from ambient noise and earthquake surface waves show apparent differences in patterns of azimuthal anisotropy in the upper crust and upper mantle beneath SE Tibet, suggesting radial variations in crust-mantle deformation styles. However, similarity between (instantaneous) surface strain field from GPS observations and fast directions of shear wave splitting (thought to be representative of upper mantle deformation) suggests vertically coherent deformation of the crust-mantle system in SE Tibet. Future research needs to resolve this apparent discrepancy.

Strike-slip faulting appears to play a very important role in the deformation history of SE Tibet at upper and middle crustal depths. Some fault zones may act as boundaries or barriers of crustal weak zones and are likely to interplay with crustal channel flow. Therefore, integration of block extrusion in the more rigid uppermiddle crust and channel flow in the more ductile midlower crust is more compatible with current geophysical observations in SE Tibet.

In the future, various lines of research need to be conducted to better understand the structure, deformation, seismo-tectonics, and dynamics of the SE Tibet, including array-based tomography, joint inversion using multiple seismic data, and integration of geodynamic modeling and multi-geophysical observations.

Acknowledgements I appreciate the two anonymous reviewers for their constructive comments on the original manuscript paper. This research is supported by the National Natural Science Foundation of China (No. 41222028) and the Chinese Academy of Sciences/State Administration of Foreign Experts Affairs International Partnership Program for Creative Research Teams.

\section{References}

Bai D, Unsworth M J, Meju M A, Ma X, Teng J, Kong X, Sun Y, Wang L, Jiang C, Zhao C, Xiao P and Liu M (2010). Crustal deformation of the eastern Tibetan plateau revealed by magnetotelluric imaging. Nat Geosci 3: 358-362, doi:10.1038/ngeo830.

Beaumont C, Jamieson R A, Nguyen M H and Lee B (2001). Himalayan tectonics explained by extrusion of a lowviscosity channel coupled to focused surface denudation. Nature 414: 738-742.

Bensen G D, Ritzwoller M H, Barmin M P, Levshin A L, Lin F, Moschetti M P, Shapiro N M and Yang Y (2007). Processing seismic ambient noise data to obtain reliable broad-band surface wave dispersion measurements. Geophys J Int 169: 1 239-1 260.
Bensen G D, Ritzwoller M H and Shapiro N M (2008). Broadband ambient noise surface wave tomography across the United States. J Geophys Res 113: B05306, doi:10.1029/2007JB005248.

Burchfiel B C, Royden L H, van der Hilst R D, Hager B H, Chen Z, King Q W, Li C, Lu J, Yao H and Kirby E (2008). A geological and geophysical context for Wenchuan earthquake of 12 May 2008, Sichuan, People's Republic of China. GSA Today 18(7): 4-11, doi:10.1130/GSATG18A.1.

Chen M, Huang H, Yao H and van der Hilst R D (2010). Adjoint tomography using Green's functions from ambient noise. Abstract S31B-07 presented at 2010 Fall meeting, AGU, San Francisco, Calif., Dec. 13-17.

Clark M and Royden L H (2000). Topographic ooze: Building the eastern margin of Tibet by lower crustal flow. Geology 28(8): 703-706.

Cook K L and Royden L H (2008). The role of crustal strength variations in shaping orogenic plateau, with application to Tibet. J Geophys Res 113: B08407, doi:10.1029/2007JB005457.

Engdahl E R, van der Hilst R D and Buland R P (1998). Global teleseismic earthquake relocation from improved travel times and procedures for depth determination. Bull Seismol Soc Am 88: 722-743.

Flesch L M, Holt W E, Silver P G, Stephenson M, Wang C Y and Chan W W (2005). Constraining the extent of crust-mantle coupling in central Asia using GPS, geologic, and shear wave splitting data. Earth Planet Sci Lett 238: 248-268.

$\mathrm{Hu} \mathrm{S}$, He L and Wang J (2000). Heat flow in the continental area of China: A new data set. Earth Planet Sci Lett 179: 407-419.

Huang H, Yao H and van der Hilst R D (2010). Radial anisotropy in the crust of SE Tibet and SW China from ambient noise interferometry. Geophys Res Lett $\mathbf{3 7}$ : L21310, doi:10.1029/2010GL044981.

Huang J, Zhao D and Zheng S (2002). Lithospheric structure and its relationship to seismic and volcanic activity in southwest China. J Geophys Res 107(B10): 2 255, doi:10.1029/2000JB000137.

Huang R, Wang Z, Pei S and Wang Y (2009). Crustal ductile flow and its contribution to tectonic stress in Southwest China. Tectonophysics 473: 476-489.

Hubbard J and Shaw J H (2009). Uplift of the Longmenshan and Tibetan plateau, and the 2008 Wenchuan $(M=7.9)$ earthquake. Nature 458: 194-197.

Jordan T A and Watts A B (2005). Gravity anomalies, flexure and the elastic thickness structure of the IndiaEurasia collisional system. Earth Planet Sci Lett 236: 732-750, doi:10.1016/j.epsl.2005.05.036.

Kennett B L N, Engdahl E R and Buland R (1995). Constraints on the velocity structure in the earth from travel times. Geophys J Int 122: 108-124. 
Landisman M, Dziewonski A and Sato Y (1969). Recent improvements in the analysis of surface wave observations. Geophys J R astr Soc 17: 369-403.

Lev E, Long M and van der Hilst R D (2006). Seismic anisotropy in eastern Tibet from shear-wave splitting reveals changes in lithosphere deformation. Earth Planet Sci Lett 251: 293-304.

Li C, van der Hilst R D, Meltzer A S, Sun R and Engdahl E $\mathrm{R}$ (2008). Subduction of the Indian lithosphere beneath the Tibetan Plateau and Burma. Earth Planet Sci Lett 274: $157-168$.

Li H, Su W, Wang C Y and Huang Z (2009). Ambient noise Rayleigh wave tomography in western Sichuan and eastern Tibet. Earth Planet Sci Lett 282: 201-211, doi:10.1016/j.epsl.2009.03.021.

Li H, Su W, Wang C Y, Huang Z and Lü Z (2010a). Ambient noise Love wave tomography in the eastern margin of the Tibetan plateau. Tectonophysics 491: 194-204, doi:10.1016/j.tecto.2009.12.018.

Li Y, Yao H, Liu Q, Chen J, van der Hilst R D, Li S, Huang H, Guo B, Wang J and Qi S (2010b). Phase velocity array tomography of Rayleigh waves in western Sichuan from ambient seismic noise. Chinese $J$ Geophys 53(4): 842-852 (in Chinese with English abstract).

Lin F, Moschetti M P and Ritzwoller M H (2008). Surface wave tomography of the western United States from ambient seismic noise: Rayleigh and Love wave phase velocity maps. Geophys J Int 173(1): 281-298.

Lin F, Ritzwoller M H and Snieder R (2009). Eikonal tomography: surface wave tomography by phase front tracking across a regional broad-band seismic array. Geophys $J$ Int 177(3): 1 091-1 110.

Lin F C and Ritzwoller M H (2011). Helmholtz surface wave tomography for isotropic and azimuthally anisotropic structure. Geophys J Int 186: 1 104-1 120, doi:10.1111/j.1365-246X.2011.05070.x.

Lin F C, Tsai V and Ritzwoller M H (2012a). The local amplification of surface waves: A new observable to constrain elastic velocities, density, and anelastic attenuation. J Geophys Res 117: B06302, doi:10.1029/2012JB009208.

Lin F C, Schmandt B and Tsai V C (2012b). Joint inversion of Rayleigh wave phase velocity and ellipticity using USArray: constraining velocity and density structure in the upper crust. Geophys Res Lett 39: L12303, doi:10.1029/2012GL052196.

Liu Q Y, Li Y and Chen J H (2009). Wenchuan $M_{\mathrm{S}} 8.0$ earthquake: preliminary study of the S-wave velocity structure of the crust and upper mantle. Chinese J Geophys 52 (2): 309-319 (in Chinese with English abstract).

Liu Q Y, Li Y, Chen J H, van der Hilst R D, Guo B, Wang J, Qi S and Li S C (2010). Joint inversion of receiver function and ambient noise based on Bayesian theory. Chinese J Geophys 53: 2 603-2 612 (in Chinese with
English abstract).

Molnar P, England P and Martinod J (1993). Mantle dynamics, uplift of the Tibetan Plateau, the Indian Monsoon. Rev Geophys 31: 357-396.

Mooney W D, Laske G and Masters G (1998). CRUST5.1: A global crustal model at $5^{\circ} \times 5^{\circ} . J$ Geophys Res 103 : 727-747.

Ni J F, Guzman-Speziale M, Bevis M, Holt W E, Wallace T C and Seager W (1989). Accretionary tectonics of Burma and the three-dimensional geometry of the Burma subduction zone. Geology 17: 68-71.

Nishida K, Montagner J-P and Kawakatsu H (2009). Global surface wave tomography using seismic hum. Science 326: 112, doi:10.1126/science.1176389.

Prieto G A, Lawrence J F and Beroza G C (2009). Anelastic Earth structure from the coherency of the ambient seismic field. J Geophys Res 114: B07303, doi:10.1029/2008JB006067.

Royden L H, Burchfiel B C, King R W, Wang E, Chen Z L, Shen F and Liu Y P (1997). Surface deformation and lower crustal flow in eastern Tibet. Science 276: 788790.

Royden L H, Burchfiel B K and van der Hilst R D (2008). The geological evolution of the Tibetan Plateau. Science 321: 1 054-1 058.

Sabra K G, Gerstoft P, Roux P and Kuperman W A (2005). Surface wave tomography from microseisms in Southern California. Geophys Res Lett 32: L14311, doi:10.1029/ 2005 GL023155.

Savage M K (1999). Seismic anisotropy and mantle deformation: What have we learned from shear wave splitting? Rev Geophys 37: 65-106.

Shapiro N M and Campillo M (2004). Emergence of broadband Rayleigh waves from correlations of the ambient seismic noise. Geophys Res Lett 31: L07614, doi:10.1029/2004GL019491.

Shapiro N M, Campillo M, Stehly L and Ritzwoller M H (2005). High-resolution surface wave tomography from ambient seismic noise. Science 307: 1 615-1 618.

Shen Y, Ren Y, Gao H and Savage B (2012). An improved method to extract very broadband empirical Green's functions from ambient seismic noise. Bull Seismol Soc Am 102(4): $1872-1877$.

Snieder R (2004). Extracting the Green's function from the correlation of coda waves: A derivation based on stationary phase. Phys Rev E 69: 046610.

Sol S, Meltzer A, Burgmann R, van der Hilst R D, King R, Chen Z, Koons P, Lev E, Liu Y P, Zeitler P K, Zhang X, Zhang J and Zurek B (2007). Geodynamics of southeastern Tibet from seismic anisotropy and geodesy. Geology 35: 563-566, doi:10.1130/G23408A.1.

Su W, Wang C Y and Huang Z X (2008). Azimuthal anisotropy of Rayleigh waves beneath the Tibetan plateau and adjacent areas. Science in China (Series D) 
51(12): $1717-1725$.

Sun X, Song X, Zheng S, Yang Y and Ritzwoller M H (2010). Three dimensional shear velocity structure of the crust and upper mantle beneath China from ambient noise surface wave tomography. Earthquake Science 23: 449-463, doi:10.1007/s11589-010-0744-4.

Tapponnier P, Peltzer G, Le Dain A Y, Armijo R and Cobbold P (1982). Propagating extrusion tectonics in Asia: New insights from simple experiments with plasticine. Geology 10: 611-616.

Tapponnier P, Xu Z, Roger F, Meyer B, Arnaud N, Wittlinger G and Yang J (2001). Oblique stepwise and growth of the Tibet plateau. Science 294: 1 671-1 677.

Tromp J, Luo Y, Hanasoge S and Peter D (2010). Noise cross-correlation sensitivity kernels. Geophys J Int 183: 791-819, doi:10.1111/j.1365-246X.2010.04721.x.

Wang C Y, Chan W and Mooney W (2003). Threedimensional velocity structure of crust and upper mantle in southwestern China and its tectonic implications. $J$ Geophys Res 108(B9): 2442, doi:10.1029/2002JB001973.

Wang C Y, Flesch L M, Silver P G, Chang L J and Chan W W (2008). Evidence for mechanically coupled lithosphere in central Asia and resulting implication. Geology 36: 363-366, doi:10.1130/G24450A.1.

Wang C Y, Lou H, Silver P G, Zhu L and Chang L (2010). Crustal structure along $30^{\circ} \mathrm{N}$ in the eastern Tibetan Plateau and its tectonic implications. Earth Planet Sci Lett 289: 367-376, doi:10.1016/j.epsl.2009.11.026.

Xu L, Rondenay S and van der Hilst R D (2007). Structure of the crust beneath the southeastern Tibetan Plateau from teleseismic receiver functions. Phys Earth Planet Int 165: 176-193, doi:10.1016/j.pepi.2007.09.002.

Yang Y, Ritzwoller M H, Levshin A L and Shapiro N M (2007). Ambient noise Rayleigh wave tomography across Europe. Geophys J Int 168: 259-274.

Yang Y, Li A and Ritzwoller M H (2008). Crust and uppermost mantle structure in southern Africa revealed from ambient noise and teleseismic tomography. Geophys J Int 174: 235-248, doi:10.1111/j.1365-246X.2008.03779.x.

Yang Y, Ritzwoller M H, Zheng Y, Shen W, Levshin A L and Xie Z (2012). A synoptic view of the distribution and connectivity of the mid-crustal low velocity zone beneath Tibet. J Geophys Res 117: B04303, doi:10.1029/2011JB008810.

Yao H, Xu G, Zhu L and Xiao X (2005). Mantle structure from inter-station Rayleigh wave dispersion and its tectonic implication in western China and neighboring regions. Phys Earth Planet Inter 148: 39-54.

Yao H, van der Hilst R D and de Hoop M V (2006). Surfacewave array tomography in SE Tibet from ambient seismic noise and two-station analysis - I. phase velocity maps. Geophys J Int 166: 732-744.

Yao H, Beghein C and van der Hist R D (2008). Surfacewave array tomography in SE Tibet from ambient seismic noise and two-station analysis: II - Crustal and upper-mantle structure. Geophys J Int 163: 205-219, doi:10.1111/j.1365-246X.2007.03696.x.

Yao H and van der Hilst R D (2009). Analysis of ambient noise energy distribution and phase velocity bias in ambient noise tomography, with application to SE Tibet. Geophys J Int 179: 1 113-1 132, doi:10.1111/j.1365246X.2009.04329.x.

Yao H, van der Hilst R D and Montagner J P (2010). Heterogeneity and anisotropy of the lithosphere of SE Tibet from surface wave array tomography. J Geophys Res 115: B12307, doi:10.1029/2009JB007142.

Yao H, Gouedard P, McGuire J, Collins J and van der Hilst R D (2011). Structure of young East Pacific Rise lithosphere from ambient noise correlation analysis of fundamental- and higher-mode Scholte-Rayleigh waves. C R Geoscience 343: 571-583, doi:10.1016/j.crte.2011.04.004.

Yi G, Yao H, Zhu J and van der Hilst R D (2010). Lithospheric deformation of continental China from Rayleigh wave azimuthal anisotropy. Chinese J Geophys 53: 256268, doi:10.3969/j.issn.0001-5733.2010.02.004 (in Chinese with English abstract).

Yin A and Harrison T M (2000). Geologic evolution of the Himalayan-Tibetan orogeny. Annu Rev Earth Planet Sci 28: 211-280.

Zhang H, Maceira M, Yao H and van der Hilst R D (2011). Joint imaging of the crust beneath the southeastern margin of the Tibetan plateau using body wave travel times and surface wave dispersion curves. Abstract T53E-08 presented at 2011 Fall meeting, AGU, San Francisco, Calif., Dec. 5-9.

Zhang P, Shen Z, Wang M, Gan W, Burgmann R, Molnar P, Wang Q, Niu Z, Sun J, Wu J, Sun H and You X (2004). Continuous deformation of the Tibetan Plateau from global positioning system data. Geology 32(9): 809812.

Zhang P Z, Wen X Z, Shen Z K and Chen J H (2010). Oblique, high-angle, listric-reverse faulting and associated development of strain: the Wenchuan earthquake of May 12, 2008, Sichuan, China. Annu Rev Earth Planet Sci 38: 353-382, doi:10.1146/annurevearth-040809-152602.

Zhang Z, Wang Y, Chen Y, Houseman G A, Tian X, Wang $\mathrm{E}$ and Teng J (2009). Crustal structure across Longmenshan fault belt from passive source seismic profiling. Geophys Res Lett 36: L17310, doi:10.1029/2009GL039580.

Zheng S H, Sun X L, Song X D, Yang Y J and Ritzwoller M $\mathrm{H}$ (2008). Surface wave tomography of China from ambient seismic noise correlation. Geochem Geophys Geosyst 9: Q05020, doi:10.1029/2008GC001981.

Zheng Y, Yang Y, Ritzwoller M H, Zheng X, Xiong X and Li Z (2010). Crustal structure of the northeastern Tibetan Plateau, the Ordos block and the Sichuan basin from ambient noise tomography. Earthquake Science 23: 465-476, doi:10.1007/s11589-010-0745-3. 